\title{
TECHNOLOGIES TO MAXIMISE PRE-FLOWER SPRAY APPLICATIONS TO CONTROL SCALE ON KIWIFRUIT
}

\author{
R.E. GASKIN ${ }^{1}$, D.W.L. MANKTELOW ${ }^{2}$, W. MAY ${ }^{3}$ and K.D. STEELE ${ }^{1}$ \\ ${ }^{1}$ Plant Protection Chemistry ${ }_{N Z}, P$ O Box 6282, Rotorua, New Zealand \\ ${ }^{2}$ Applied Research and Technologies Ltd, PO Box 3415, Napier, New Zealand \\ ${ }^{3}$ Spray-Tec Consultants Ltd, P O Box 9227, Tauranga, New Zealand
}

Corresponding author: robyn.gaskin@ppcnz.co.nz

\begin{abstract}
The control of scale insects (Diaspididae) on kiwifruit (Actinidia chinensis) is difficult because scale inhabit sites not easily accessed by sprays. Early spring insecticide applications, which target scale living on the bark of canes and leader wood, are vital to reduce populations prior to summer. This study identified, firstly, that targeted Masotti gun, dilute spray applications increased deposits on leader vines by approximately $30 \%$, which should result in improved scale control. Secondly, using the Masotti technology, sprays applied at $2 x$ concentrate with the addition of a superspreader adjuvant increased deposits on leader wood by $>60 \%$ compared with standard volumes. The use of Masotti guns, concentrate spray applications and adjuvant addition did not increase off-target spray drift, and often reduced it, in moderate winds. Adjuvant cost can be offset against increases in work-rate efficiency for concentrate sprays, and increased deposits and target coverage are expected to improve scale control on kiwifruit leader vines from pre-flower spray applications. Keywords: Masotti gun nozzles, superspreader adjuvant, insecticide sprays, concentrate sprays, deposits, drift, Diaspididae, Actinidia chinensis.
\end{abstract}

\section{INTRODUCTION}

Insecticide applications to kiwifruit crops are made primarily to control armoured scale insects (Hemiptera: Diaspididae) (Blank 1992; Hill et al. 2006). Scale is a quarantine and cosmetic pest and must be controlled because major markets such as Korea demand scale-free fruit. Many modern insecticides currently can only be applied in early season sprays, before fruit-set, because of their long residual life. The detection of insecticide residues in fruit creates considerable market access problems for kiwifruit exports.

The control of scale insects on kiwifruit is difficult because scale are protected by a thick wax coating and inhabit sites not easily accessed by sprays, such as under bark, around buds and in lenticels. Scale are prevalent on leader vines throughout the year, and act as a source of scale infestation on leaves and fruit during spring and summer (Hill et al. 2006). Kiwifruit are usually grown on a pergola structure with vine leaders trained to grow along the pergola row and fruiting canes from these leaders trained across the pergola row. Early spring insecticide applications, which target scale living on the bark of canes and leader wood, are vital to reduce population levels prior to summer. In addition, spray coverage of vines is easier when no leaves are present.

The work reported here was undertaken to optimise pre-flower spray applications to control scale. Better targeting of leader wood was attempted by modifying nozzles and sprayer outputs. A super-spreading adjuvant was included in sprays to maximise spray deposits and coverage (Gaskin et al. 2000) of leader wood bark and crevices. This provided the option of lowering spray application volumes, with the potential to reduce off-target spray drift. 


\section{METHODS AND MATERIALS \\ Spraylab and sprayer setup}

This study was conducted in January 2008 in the Scion Long Mile research nursery, Rotorua. Mean wind speeds varied from 1.4-1.9 m/s (Table 1) and were typical of those under which spraying would normally be undertaken. A single bay pergola structure was constructed $(5 \times 5 \mathrm{~m}$, by $2 \mathrm{~m}$ high) as described in Gaskin et al. (2008), and treatments were applied using a trailed Fantini ARI KIWI-VAC 2000 airblast sprayer, fitted with a front entry axial fan and a new type of air output straightening vanes that were designed to better profile sprayer air output to pergola kiwifruit canopies. They produce less air through the top section of the fan compared to conventional sprayers, and direct relatively even air out each side of the sprayer towards the vine leader region. The sprayer was operated with the fan in the low gearbox setting with a measured air output of ca $23,000 \mathrm{~m}^{3} / \mathrm{h}$ and an air output speed at the spray nozzles of $18-23 \mathrm{~m} / \mathrm{s}$. The sprayer was fitted with seven nozzles on each side, with nozzle positions 3,4 and 5 (position $1=$ the top nozzle and nozzles 1, 2, 6 and 7 were off) used to direct spray output to the leader region. The operating positions had Masotti Article 58 ceramic disk and stainless steel core solid cone nozzles with approximately $40^{\circ}$ output angles fitted (current standard industry practice). To more accurately direct a concentrated band of spray into the leader region, two short Masotti gun nozzles were set in nozzle positions 2 and 4 (instead of the industry standard disc and core nozzles), to deliver a narrow spray output cone angle (jetting position ca $20^{\circ}$ output angle), in combination with one solid cone disk and core nozzle. The sprayer was calibrated to deliver two different output volumes, 1100 and 550 litres/ha, where the higher volume represented typical current industry practice to wet this target to the point of runoff (Table 1). It is important to note that the bulk of the spray volume was directed into a narrow band of approximately 1.5 metres in width, which contained the canopy leader wood. If the same spray volume was directed across the entire five metre row width the application volume would have been over 3500 litres/ha. Operating pressures and droplet size profiles were kept as similar as possible between the two application volume treatments. A low-drift air inclusion (AI) nozzle treatment was included to determine whether leaders could be effectively targeted using these types of nozzles and to provide a benchmark for comparison of relative off-target losses. In this case, three narrow angle ( $40^{\circ}$ output) Agrotop Turbo Drop AI nozzles were used in nozzle positions 3,4 and 5 of the spray ring, with all other nozzles turned off.

\section{Treatments}

Four treatments were applied (Table 1), based on results from a preliminary study (data not presented). The AI nozzle application was based on the sprayer setup recommended for reducing spray drift from hydrogen cyanamide sprays (Gaskin et al. 2008). The intention was to repeat all treatments as sprayed replicates, but fickle winds prevented this; only treatments 1 and 3 (Table 1) were repeated successfully. Tartrazine food dye was included in all treatments $(2.5 \mathrm{~g} /$ litre $)$ as a tracer to quantify spray deposits. Two adjuvants were included: Latron ${ }^{\circledR}$ B-1956 (LB; Dow Agrosciences) in all dilute, high volume sprays at $20 \mathrm{ml} / 100$ litres $(220 \mathrm{ml} / \mathrm{ha}$ ), and Du-Wett@ (DW; Elliott Technologies Ltd) at $50 \mathrm{ml} / 100$ litres $(275 \mathrm{ml} / \mathrm{ha})$ in all low volume sprays.

Treatments were applied at $5.2 \mathrm{~km} / \mathrm{h}$ by spraying an $80 \mathrm{~m}$ simulated row length at right angles to the wind. The first treatment pass was made, with both sides of the sprayer operating, through the centre of the pergola structure that held the leader and cane targets. Upwind and downwind sides of the pergola were then individually sprayed, spraying in towards the pergola centre, with only that side of the sprayer operating.

\section{Deposit assessments}

Leader wood was sampled from the Plant \& Food Research orchard at Te Puke. 'Hayward' vines were selected to represent a wide range of thicknesses and tortuosity. Sections containing a minimum length $(30 \mathrm{~cm})$ of wood of fairly even circumference were cut, and staples were hammered into each end of the section. A length of wire was attached between the staples and was used to hang the leader sections on the pergola wires. Two leader sections were suspended on each side of the pergola (upwind and 
downwind), parallel to the line of travel of the sprayer. After spray treatments had dried, leader targets were sampled by sawing out a $20-\mathrm{cm}$ long sub-section of wood. Each sub-section was immediately washed in $200 \mathrm{ml}$ of water to recover dye deposits and then stored individually in resealable plastic bags. Lengths, and diameters at both ends and in the middle, of the leader sub-sections were used to estimate the surface area of each sample.

One-year-old 'Hayward' canes, which had been sampled 5 months earlier and coolstored until required, were also used as deposit targets. Four canes ( $>2 \mathrm{~m}$ length) were randomly selected and tied into the pergola edge (two on each of upwind and downwind sides) parallel to the line of travel of the sprayer. After spray treatments had dried, cane targets were sampled and processed as described in Gaskin et al. (2006). Briefly, they were measured to determine surface area and washed to recover dye and quantify spray deposits. Deposits were calculated as dose $\left(\mu \mathrm{g} / \mathrm{cm}^{2}\right)$ normalised to $1 \mathrm{~kg}$ a.i. applied per ha. Results were statistically analysed using ANOVA to determine the significance of treatment on spray deposits retained on leader and cane sections.

Wind speed and direction were recorded during each treatment as described in Gaskin et al. (2008). Drift sampling was undertaken on the downwind side only of the sprayed plot, on $5 \mathrm{~m}$ long vertical nylon trimmer lines located $10 \mathrm{~m}, 15 \mathrm{~m}$ and $25 \mathrm{~m}$ from the closest sprayer output ( 3 replicate lines at each distance), as described in Gaskin et al. (2008). Briefly, lines were washed, spray deposits quantified and surface areas of lines determined. Deposits were calculated as dose $\left(\mu \mathrm{g} / \mathrm{cm}^{2}\right)$ normalised to $1 \mathrm{~kg}$ a.i. applied per ha. Results were statistically analysed using ANOVA to determine the significance of treatment on distance and height of off-target spray deposits.

\section{RESULTS}

The targeted low volume Masotti gun treatments gave significantly higher deposits on canes (Table 1). This trend was also apparent with the leader wood samples. However, variability in deposits, due to their non-uniformity of size, shape and surface, reduced the statistical significance of treatment effects on leaders $(\mathrm{P}=0.06)$. The low volume Masotti guns application (+DW adjuvant) increased mean deposits on leaders, by at least $60 \%$ relative to the standard high volume (+LB adjuvant) treatment (Table 1 ). The same trend was evident on canes, where the guns+DW treatment significantly increased mean deposits by more than $50 \%$ relative to the standard high volume sprays (Table 1 ).

The use of Masotti guns to target the dilute spray tended to increase deposits on leaders relative to the standard airblast spray, by approximately $30 \%$ (Table 1 ). The AI nozzles performed similarly to the standard treatment in this study, with respect to mean deposits on leaders (Table 1) and gave slightly higher deposits on canes. Narrow angle AI nozzles ( $40^{\circ}$ output) were used, but these still gave a wider output plume than was desired. The use of narrower angle nozzles could be expected to improve leader deposits. Leaders and canes positioned on the downwind side of the pergola always received slightly higher deposits than those on the upwind side, by about $20 \%$ over all targets (data not presented). This difference would be compensated for in a full orchard spray across multiple rows. 
TABLE 1: Deposits $\left(\mu \mathrm{g} / \mathrm{cm}^{2}\right.$, normalised to a $1 \mathrm{~kg} / \mathrm{ha}$ application of dye) on leader and cane wood, from sprays applied with varying sprayer setups, adjuvants and spray volumes.

\begin{tabular}{llccc}
\hline \multirow{2}{*}{$\begin{array}{l}\text { Trt } \\
\text { no. }\end{array}$} & Trt description & Mean wind & \multicolumn{2}{c}{ Target } \\
\cline { 4 - 5 } & Setup+adjuvant, spray vol. & speed $(\mathrm{m} / \mathrm{s})$ & Leaders & Canes \\
\hline 1 & Std+LB, 1100 litres/ha & 1.9 & $8.0 \mathrm{~b}^{1}$ & $7.4 \mathrm{c}$ \\
$1 \mathrm{R}$ & Std+LB, 1100 litres/ha & 1.4 & $7.3 \mathrm{~b}$ & $5.8 \mathrm{~d}$ \\
2 & Std\&guns+LB, 1100 litres/ha & 1.6 & $10.0 \mathrm{ab}$ & $6.4 \mathrm{~cd}$ \\
3 & Std\&guns+DW, 550 litres/ha & 1.4 & $13.0 \mathrm{a}$ & $11.2 \mathrm{a}$ \\
$3 \mathrm{R}$ & Std\&guns+DW, 550 litres/ha & 1.5 & $13.6 \mathrm{a}$ & $11.5 \mathrm{a}$ \\
4 & AI setup+DW, 550 litres/ha & 1.5 & $7.7 \mathrm{~b}$ & $9.1 \mathrm{~b}$ \\
\hline
\end{tabular}

${ }^{1}$ Means within columns sharing common postscripts are not significantly different (LSD, $\mathrm{P}=0.05$ ).

Treatment had a significant effect $(\mathrm{P}<0.001)$ on off-target spray losses (drift), both on horizontal distance from the sprayer $(\mathrm{P}<0.001$; Table 2$)$ and on vertical height above the ground $(\mathrm{P}<0.01$, data not presented). As expected, drift decreased with increasing distance (and height) from the sprayer. Overall, the standard high volume application produced greatest off-target drift and the AI nozzle setup, the least. The use of Masotti guns and concentrate sprays did not increase drift relative to the standard high volume application and often reduced it (Table 2).

TABLE 2: Deposits ( $\mu \mathrm{g} / \mathrm{cm}^{2}$, normalised to a $1 \mathrm{~kg} / \mathrm{ha}$ application of dye) recovered from drift collection poles located 10,15 and $25 \mathrm{~m}$ downwind from the sprayer. Sprays were applied with varying sprayer setups, adjuvants and spray volumes.

\begin{tabular}{llcccc}
\hline \multirow{2}{*}{$\begin{array}{l}\text { Trt } \\
\text { no. }\end{array}$} & $\begin{array}{l}\text { Trt description } \\
\text { Setup+adjuvant, spray vol. }\end{array}$ & \multicolumn{3}{c}{ Collection pole distance } & \multirow{2}{*}{ Trt } \\
\cline { 3 - 5 } 1 & Std+LB, 1100 litres/ha & 0.82 & 0.44 & 0.13 & $0.46 \mathrm{a}^{1}$ \\
$1 \mathrm{R}^{2}$ & Std+LB, 1100 litres/ha & - & - & - & - \\
2 & Std\&guns+LB, 1100 litres/ha & 0.53 & 0.31 & 0.16 & $0.33 \mathrm{~b}$ \\
3 & Std\&guns+DW, 550 litres/ha & 0.70 & 0.19 & 0.07 & $0.32 \mathrm{~b}$ \\
$3 \mathrm{R}$ & Std\&guns+DW, 550 litres/ha & 0.46 & 0.38 & 0.18 & $0.34 \mathrm{~b}$ \\
4 & AI setup+DW, 550 litres/ha & 0.25 & 0.14 & 0.05 & $0.15 \mathrm{c}$ \\
\hline LSD (P=0.05) & $-----------0.15----------$ & \\
Pole position mean & $0.55 \mathrm{~A}$ & $0.29 \mathrm{~B}$ & $0.12 \mathrm{C}$ & \\
\hline
\end{tabular}

${ }^{1}$ Means within column sharing common postscripts are not significantly different.

${ }^{2}$ Wind changed direction during spraying, so downwind drift data were compromised. 


\section{DISCUSSION}

Despite the limited treatment replication possible in this experiment, the deposit trends seen on canes and leader wood support two important concepts for maximising potential spray deposits and use efficiency. The first is that greatest deposits can be achieved when the sprayer output is efficiently directed towards the spraying target, and the second is that the use of spray application volumes below the point of runoff will provide higher chemical retention on the target than the use of application volumes in which runoff occurs.

This experiment measured deposits on canes and leader wood. A preliminary experiment (data not presented) tested similar treatments using artificial turf strips wrapped around PVC pipes to simulate leader wood. The spray deposit trends from both experiments were the same. Effective spray coverage and control of cryptic pests on complex targets like kiwifruit leader wood requires that the bulk of the spray output is accurately directed into the target. In this case the use of narrow angle spray nozzles set in multiple directions achieved a significant lift in spray deposits over more conventional nozzling. In both sprayer setups it was estimated that over half of the sprayer output will miss the immediate leader target and will be lost as overspray. This overspray is considered important in that it provides some coverage and control of any scale populations that have managed to overwinter on (the less desirable habitat of) fruiting canes in adjacent rows. Very little of the spray droplets in any overspray are observed to reach leader wood in adjacent rows. Thus, the most efficient and effective spray application and coverage is achieved by accurately directing the spray plume to the leader target in the immediate rows.

The use of high spray application volumes is a common strategy for achieving coverage and wetting of cryptic pests on complex targets. Concentrate spray applications can typically increase average deposit levels by $15-30 \%$ over those from dilute applications (Manktelow 1998). However, spray coverage and target wetting can be compromised in low volume applications. While spray coverage was not quantified in this study, it was visibly improved by DW adjuvant in the low volume spray. DW adjuvant has been shown to increase spray deposits on a variety of plants, particularly when sprays are concentrated and the target is difficult-to-wet (Gaskin et al. 2000, 2004a,b). This adjuvant is not recommended for use in dilute sprays as run-off may occur, but its superspreading capacity ensures that concentrate spray will access fissures in bark that harbour scale more efficiently than sprays without the adjuvant. This is expected to improve scale control on leader vines. Adjuvant cost can be offset against increases in work-rate efficiency. The low volume, concentrate application did not compromise the amount of spray deposited on leaders and canes, and use of this technique will increase the productivity of kiwifruit spraying operations.

The use of Masotti guns, reduced spray application volumes and addition of Du-Wett adjuvant had no adverse effects on off-target spray drift. AI nozzle technology could be used to deliver scale sprays to leader vines, but a different set of nozzles would be recommended than those currently used for hydrogen cyanamide applications. If offtarget spray losses from leader spray applications become an issue for the industry, it is expected that AI nozzles could provide a reasonable compromise between spray delivery to the target and drift mitigation. However, further work would be required to identify an optimal nozzle configuration for this spraying target.

\section{ACKNOWLEDGEMENTS}

Thanks to R \& R tractors (Te Puke) for providing the sprayer and tractor. Scion kindly provided the research site and Elliott Technologies Ltd (Pukekohe) supplied Du-Wett adjuvant. The hard workers during these studies were Rebecca van Leeuwen, Alison Forster, Amin Pathan, Mark Geddes, David Horgan and Guy Arnold. Funding was provided by NZ Kiwifruit Growers Inc. and the MAF Sustainable Farming Fund. 


\section{REFERENCES}

Blank RH 1992. A review of dormant season and pre-blossom sprays on kiwifruit in New Zealand. Acta Horticulturae (ISHS) 297: 509-516.

Gaskin RE, Elliott G, Steele KD 2000. Novel organosilicone adjuvants to reduce agrochemical spray volumes on row crops. New Zealand Plant Protection 53: 350-354.

Gaskin RE, Manktelow DW, Elliott GS 2004a. Adjuvant prescriptions to lower water volumes and improve disease control in vineyards. Proceedings of the $7^{\text {th }}$ International Symposium on Adjuvants for Agrochemicals, Capetown, South Africa [ISBN 1-920-01716-X]. 6 p.

Gaskin RE, Manktelow DW, Skinner SJ, Elliott G 2004b. Use of a superspreader adjuvant to reduce spray application volumes on avocados. New Zealand Plant Protection 57: 266-270.

Gaskin RE, Manktelow DW, Steele KD 2006. Adjuvant and application technologies to minimise off-target drift from kiwifruit sprays. New Zealand Plant Protection 59: 217-222.

Gaskin RE, Manktelow DW, May W, Max S 2008. Development of Best Practice to minimise off-target drift from hydrogen cyanamide sprays in kiwifruit orchards. New Zealand Plant Protection 61: 153-158.

Hill MG, Mauchline NA, Ramankutty P 2006. Armoured scale insect infestation on kiwifruit in relation to position on the vine. New Zealand Plant Protection 59: 47-50.

Manktelow DWL 1998. Factors affecting spray deposits and their biological effects on New Zealand apple canopies. PhD thesis, Massey University, Palmerston North, New Zealand. 